\title{
A Raman Study of Diamond Film Growth on Co-Cemented Tungsten Carbide
}

\author{
Riccardo Polini and Enrico Traversa
}

Dipartimento di Scienze e Tecnologie Chimiche, Università di Roma “Tor Vergata," 00133 Roma, Italy

\author{
Alessandra Marucci and Giorgio Mattei
}

Insituto di Metodologie Avanzate Inorganiche del CNR, 00016 Monterotondo Scalo (Roma), Italy

\author{
Giancarlo Marcheselli \\ Fabbrica Italiana Leghe Metalliche Sinterizzate (FILMS) S.p.A., 28020 Anzola d'Ossola (Novara), Italy
}

\begin{abstract}
Phase purity and crystallinity of diamond films grown by hot filament chemical vapor deposition on ISO-grade K10 cemented carbide [94.2 weight percent (w/o) WC-5.8 w/o Co] were studied by Raman spectroscopy as a function of substrate temperature, gas phase composition, and substrate pretreatments. High-quality diamond films were grown using $0.5 \% \mathrm{CH}_{4} / \mathrm{H}_{2}$ in a rather narrow range of substrate temperatures $\left(750\right.$ to $\left.760^{\circ} \mathrm{C}\right)$. In all the deposited coatings, the firstorder Raman band of diamond is detected at $1337 \mathrm{~cm}^{-1}$. This fact indicates that a $2 \mathrm{GPa}$ residual compressive stress is present in the diamond phase. The linewidth of the diamond Raman peak increases with deposition temperature. This effect has been ascribed to a higher density of defects in diamond crystallites. It has been observed that Co removal from the substrate surface by wet chemical etching before deposition is less effective than a careful selection of deposition parameters to reduce the codeposition of nondiamond carbon phases. This finding has been attributed to the fast diffusion of the binder from the bulk to the substrate surface, even for the etched substrates.
\end{abstract}

\section{Introduction}

The chemical vapor deposition (CVD) of diamond films on cemented carbides allows the development of cutting tools with improved cutting performance and durability. ${ }^{1-7}$ The fundamental drive for the use of diamond films as hard coatings on cemented carbide tools is based on the possibility of combining the toughness of cemented carbide with the exceptional wear resistance of diamond. Nevertheless, many difficulties must be overcome in the diamond CVD when cobalt is used as a binder. In fact, the Co-rich binder phase can reduce the formation of stable diamond nuclei in the early stages of the deposition process. ${ }^{8}$ Moreover, the diffusion of the metallic binder through the growing diamond films, observed by Mehlmann et al., ${ }^{9}$ leads to the codeposition of undesired phases, namely, amorphous carbon, and graphite. The dissolution of diamond into cobalt during the deposition process has been also reported; Kubelka et al. ${ }^{10}$ found that the lattice parameter of Co increased distinctly during the CVD process, reflecting the incorporation of carbon in the binder phase even after the substrate surface was completely covered by diamond. This implies that the carbon dissolution, once the substrate is coated, proceeds via dissolution of the diamond film at the diamond/hard metal substrate interface. Therefore, the presence of Co in cemented carbides has been found to be detrimental to diamond growth, crystallinity, phase purity, and film adhesion. Various methods have been proposed to overcome the deleterious effect of Co. In order to improve the adhesion strength of diamond film on WC-Co inserts, the use of intermediate layers has been proposed. ${ }^{11,12}$ The transformation of $\mathrm{Co}$ at the substrate surface into more stable compounds (such as borides or silicides) is also effective in reducing the codeposition of nondiamond carbon as well as increasing film adhesion. ${ }^{13}$ The most common approach for solving the problems related to the presence of the binder is its removal from the substrate surface by wet etching with diluted $\mathrm{H}_{2} \mathrm{SO}_{4},{ }^{14}$ diluted $\mathrm{HNO}_{3},{ }^{1,6,15-19}$ or $\mathrm{H}_{2} \mathrm{O}_{2}: \mathrm{H}_{2} \mathrm{SO}_{4}=9: 1$. $^{20}$

Although it is generally accepted that the primarily wet etching of the substrate is effective in improving both quality and adhesion of the diamond coating, literature data usually report comparative results between etched and untreated samples deposited in a narrow substrate temperature range. In this paper we report a quantitative Raman study on phase purity and crystallinity of diamond films grown on etched and unetched Co-cemented tungsten carbide in a wide range of substrate temperatures.

\section{Experimental}

Samples $10 \times 10 \times 3 \mathrm{~mm}$ made of ISO-grade $\mathrm{K} 10$ cemented carbide $(94.2 \mathrm{w} / \mathrm{o} \mathrm{WC}-5.8 \mathrm{w} / \mathrm{o} \mathrm{Co})$ were used as substrates. After the sintering process, all the samples were ground and then machined to bore a hole $(3 \mathrm{~mm}$ diam and $2 \mathrm{~mm}$ deep) in the center of the face not subjected to diamond deposition. This hole accommodated the $\mathrm{Pt} / \mathrm{Pt}-$ Rh $10 \%$ thermocouple used to measure the substrate temperature $\left(650\right.$ to $\left.950^{\circ} \mathrm{C}\right)$ during the deposition process. In order to enhance diamond nucleation, the as-ground samples were submitted to 5 min scratching with $15 \mu \mathrm{m}$ diamond powder suspension (DP Suspension, HQ by Struers) and to further $30 \mathrm{~s}$ scratching with $1 \mu \mathrm{m}$ diamond paste (DP-Paste, $P$ by Struers). From here on the substrates are indicated as S, scratched, samples. Following the abrading treatment, the samples were washed with acetone and ethanol in an ultrasonic vessel. Several samples were also submitted to 5 min etching with $\mathrm{HNO}_{3}: \mathrm{H}_{2} \mathrm{O}=1: 1$ in the ultrasonic vessel, hereafter indicated $\mathrm{SE}$, scratched and etched, samples. After the etching treatment, the samples were washed with deionized water and the weight loss was $0.2 \%$. Diamond synthesis was performed in a stainless steel hot filament CVD (HFCVD) reactor previously described. ${ }^{18}$ The gas phase, a mixture of hydrogen (purity $99.99990 \%$ ) and methane (purity $99.995 \%$ ) with $\mathrm{CH}_{4} / \mathrm{H}_{2}$ volume ratios fixed at 1.0 or $0.5 \%$, was activated by a tantalum filament accurately positioned by means of a cathetometer $0.80 \mathrm{~cm}$ from the substrate. A new filament was used in each deposition run without any carburizing pretreatment prior to diamond CVD. The filament temperature $\left(2185 \pm 15^{\circ} \mathrm{C}\right)$ was monitored by a two-color pyrometer. The power dissipated by the dc-heated filament was in the 180 to $200 \mathrm{~W}$ range. The total pressure of the gas mixture in the reactor was $4.8 \mathrm{kPa}$ and flow rate 300 standard $\mathrm{cm}^{3} \mathrm{~s}^{-1}$. Gas composition and flow rate were set up by digital mass flow controllers meter-kilogram-second (MKS). At the various substrate temperatures, deposition 
times were varied between 4 and $8 \mathrm{~h}$ in order to grow films with comparable thicknesses ( 2 to $2.5 \mu \mathrm{m}$ ).

All the specimens were analyzed after CVD by scanning electron microscopy (SEM, Leica Cambridge Stereoscan 360) and Raman spectroscopy. Raman spectra were recorded with a Spex Triplemate spectrograph equipped with an EG\&G Princeton Applied Research Corp. ccd OMA detector. The $514.5 \mathrm{~nm}$ line of an argon ion laser was used for excitation in a backscattering geometry with $100 \mathrm{~mW}$ on the sample (spot size $0.2 \mathrm{~mm}$ diam). The frequencies of the Raman bands were measured with $\pm 1 \mathrm{~cm}^{-1}$ uncertainty. The scattered light was not analyzed in polarization. The total counting time was $100 \mathrm{~s}$. The spectra were treated by GRAMS/386 software by Galactic to remove the base line and perform the curve fitting. In order to get the true full width at half-maximum (FWHM) of the bands, all the measured linewidths were corrected by a suitable instrumental factor, obtained taking into account the methods and the data reported in literature ${ }^{21}$ and by comparing the true FWHM of reference materials (e.g., benzene, mesytilene, m-dichlorobenzene, diamond crystal, etc.) with the ones measured at different slit widths of the spectrometer.

\section{Results and Discussion}

Stress state of the diamond phase.-Raman spectroscopy is an indirect method for the nondestructive evaluation of residual stresses in thin polycrystalline diamond coatings since the lattice strain can be derived from the measured frequencies of the zone-center phonons. ${ }^{22-24}$

Figure 1 shows the Raman spectra of the films grown at various temperatures on $\mathrm{S}$ samples using $1.0 \% \mathrm{CH}_{4}(\mathrm{a})$ and $0.5 \% \mathrm{CH}_{4}$ (b). In all the deposited films, the first-order Raman band of diamond is present at $1337 \mathrm{~cm}^{-1}$. The frequency of this peak is about $5 \mathrm{~cm}^{-1}$ blue shifted with respect to the value of natural diamond $\left(1332.4 \mathrm{~cm}^{-1}\right.$ at atmospheric pressure and $25^{\circ} \mathrm{C}$ ). This shift does not significantly change with deposition temperature and indicates a residual compressive stress in the diamond phase. Sharma et al. ${ }^{25}$ reported a pressure coefficient for diamond of $2.37 \mathrm{~cm}^{-1} \mathrm{GPa}^{-1}$ and Tardieu et al. ${ }^{26}$ obtained a pressure coefficient of $2.64 \mathrm{~cm}^{-1} \mathrm{GPa}^{-1}$. Therefore, using an average pressure coefficient of $2.5 \mathrm{~cm}^{-1} \mathrm{GPa}^{-1}$, it is possible to estimate a $2 \mathrm{GPa}$ residual compressive stress in the deposited diamond originating from the different thermal expansion coefficients of diamond and cemented tungsten carbide. This value is in good agreement with the residual thermal stress $\left(\sigma_{\text {thermal }}\right)$ which can be calculated according to the following relationship ${ }^{23}$

$$
\sigma_{\text {thermal }}=\left(\alpha_{\text {dia }}-\alpha_{\text {sub }}\right) \Delta T E_{\text {dia }} /(1-v)
$$

where $\alpha_{\mathrm{dia}}=3.15 \times 10^{-6} \mathrm{~K}^{-1}$ is the average thermal expansion coefficient of diamond in the 130 to $930^{\circ} \mathrm{C}$ temperature range, $\alpha_{\text {sub }}=5.5 \times 10^{-6} \mathrm{~K}^{-1}$ is the average thermal expansion coefficient of ISO-grade K10 cemented carbide in the 20 to $800^{\circ} \mathrm{C}$ temperature range, $\Delta T$ is the difference between substrate temperature during CVD and room temperature, $E_{\text {dia }}$ is the Young's modulus of diamond ( $1 \mathrm{TPa}$ ), and $v$ is the Poisson ratio of the film (0.07). By using Eq. 1, it is possible to evaluate a residual compressive stress of 1.6 to $2.3 \mathrm{GPa}$ in the temperature range investigated, thereby corresponding to Raman shifts in the 1336 to 1338 $\mathrm{cm}^{-1}$ wave number range. Due to our experimental uncertainty in measuring Raman band positions $\left( \pm 1 \mathrm{~cm}^{-1}\right)$, it was not possible to distinguish between different stress states for samples deposited at different temperatures.

As stated by Windischmann and Gray, ${ }^{27}$ several sources of error lurk beneath this simple procedure for stress evaluation from Raman shift. For example, the diamond Raman peak shifts to lower values with increasing temperature and excessive laser beam power density on a highly absorbing film (in which significant amounts of nondiamond carbon phases are codeposited) can give rise to a measurable red shift $\left(-0.2 \mathrm{~cm}^{-1} / 10^{\circ} \mathrm{C}\right.$, Ref. 28$)$. Moreover, to evaluate the stress in diamond films correctly, domain size correction may be required depending on the grain size.

Figure 2 shows two Raman spectra of a sample, deposited at $900^{\circ} \mathrm{C}$ using $1.0 \% \mathrm{CH}_{4}$, which was partly delaminated during cooling to room temperature. Spectrum (a) refers to the detached portion of the film with the Raman diamond peak at $1332 \mathrm{~cm}^{-1}$. Spectrum (b) refers to the
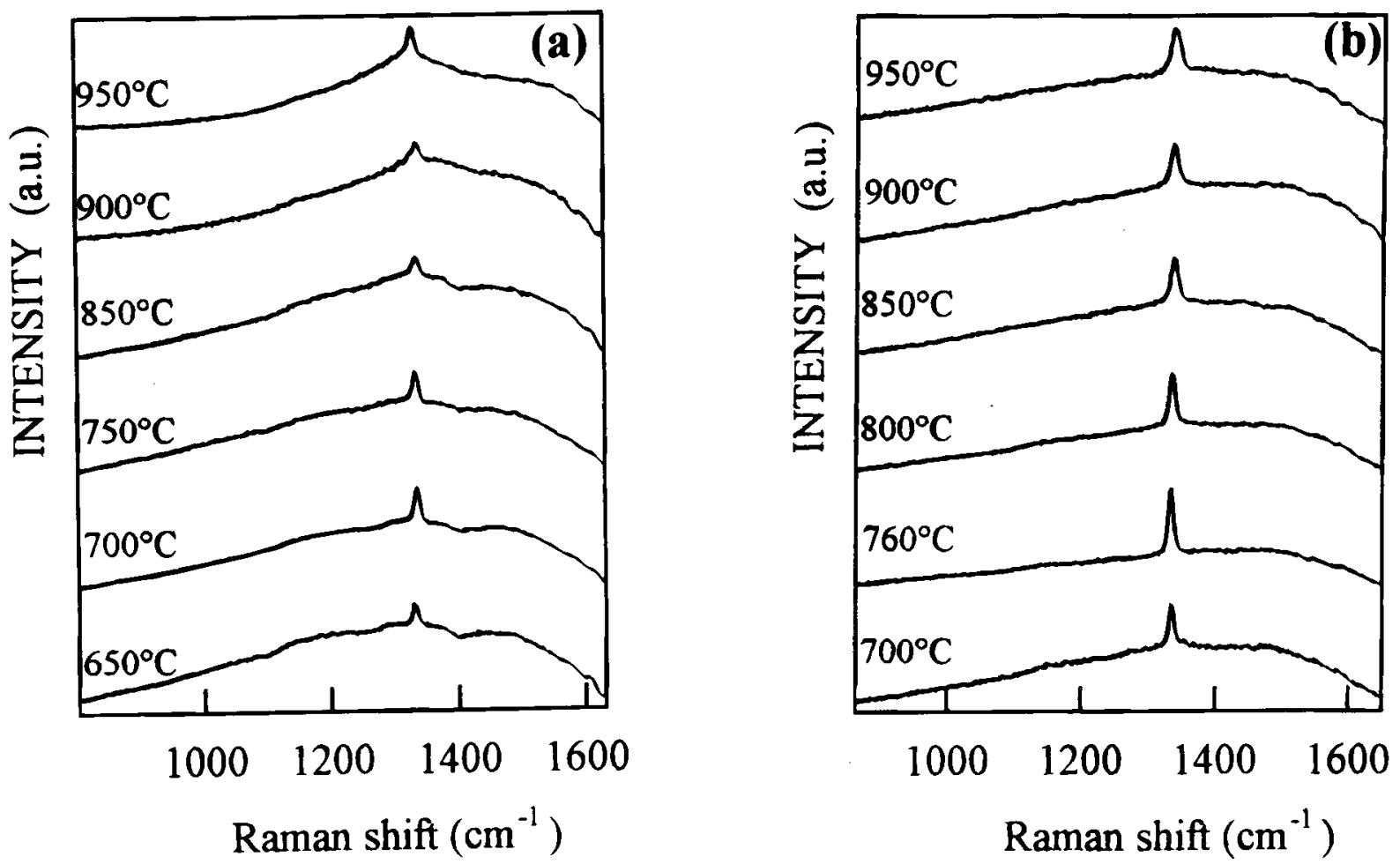

Fig. 1. Raman spectra $(\lambda=514.5 \mathrm{~nm})$ of diamond films grown on scratched $(S)$ WC-5.8 w/o Co samples at different substrate temperatures $\left(4.8 \mathrm{kPa}, 300\right.$ standard $\mathrm{cm}^{3} \mathrm{~s}^{-1}$, filament $T=2185^{\circ} \mathrm{C}$ : (a) 1.0 and (b) $0.5 \% \mathrm{CH}_{4}$. 


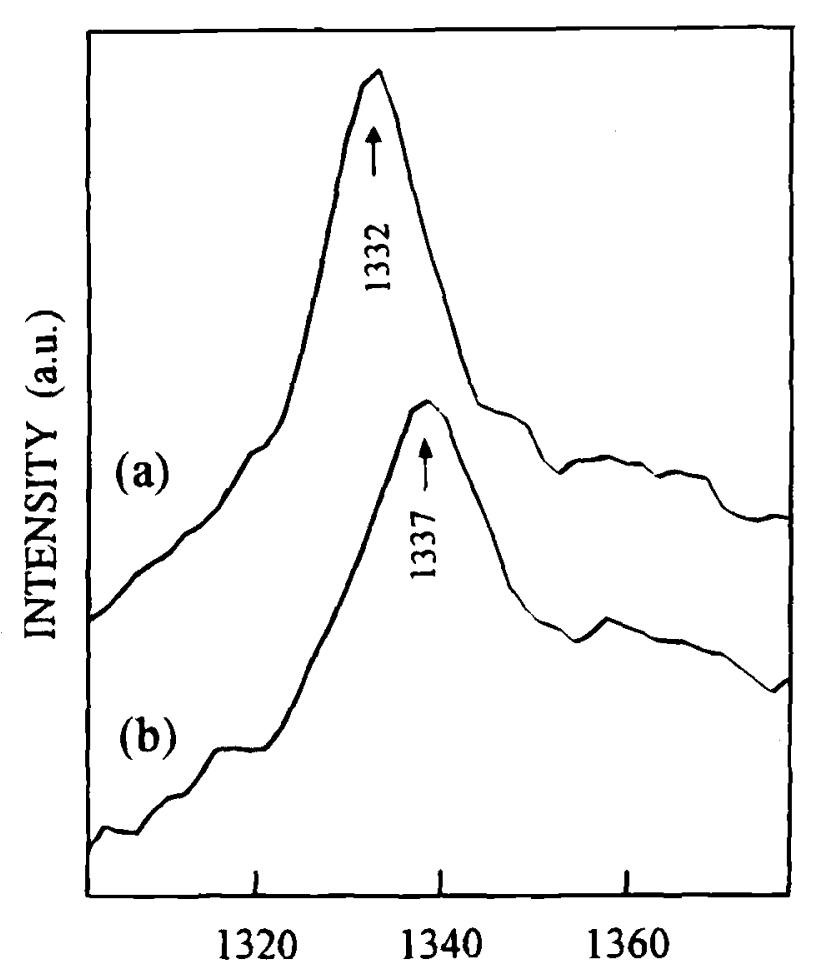

Raman shift ( $\left.\mathrm{cm}^{-1}\right)$

Fig. 2. Raman spectra $(\lambda=514.5 \mathrm{~nm})$ of a partly delaminated diamond film grown at $900^{\circ} \mathrm{C}$ on a scratched WC-5.8 w/o Co substrate $\left(1.0 \% \mathrm{CH}_{4}\right):(a)$ the delaminated portion of the film and (b) the adherent portion of the coating.

adherent portion of the coating with the diamond peak at $1337 \mathrm{~cm}^{-1}$. These findings support the hypothesis that in our samples the observed blue shift is attributable to compressive stress in the film and that such residual stress is fully released following delamination. Therefore, microstructure effects as well as laser heating of the film may be neglected.

Raman data reduction.-In order to get more information concerning the quality of the films in terms of both phase purity and crystallinity, the collected Raman spectra were subjected to the following data reduction procedure. A base line including luminescence contribution was removed and the spectra were deconvoluted, according to Bachmann and Wiechert, ${ }^{29}$ in mixed Lorentzian-Gaussian components. Figure 3 shows the results of this data treatment applied to an $\mathrm{S}$ sample deposited at $900^{\circ} \mathrm{C}(0.5 \%$ $\mathrm{CH}_{4}$ ). Besides the diamond peak, four main components contribute to the carbonaceous Raman background: a band at around $1160 \mathrm{~cm}^{-1}$, due to nanocrystalline diamond, with a breakdown of the Raman selection rule for small crystallites, a weak band at around $1480 \mathrm{~cm}^{-1}$, attributed to diamond precursors, which tends to appear simultaneously to the band at $1160 \mathrm{~cm}^{-1}{ }^{30}$ and two broad bands at 1360 and $1580 \mathrm{~cm}^{-1}$, attributable to D- and Gbands of graphite. ${ }^{29}$ Following this data treatment, the FWHM of the diamond Raman line and the ratio, $R$, of the integrated intensity of the diamond peak over the total integrated intensity of the carbonaceous components were obtained. It must be emphasized that when the $514.5 \mathrm{~nm}$ line of the Ar-ion laser is used, the scattering efficiency of $\mathbf{s p}^{2}$-bonded carbon is about 50 times larger than that of crystalline diamond, ${ }^{31}$ although adsorption of light by an amorphous phase could significantly modify the intensity of the observed scattering. Therefore, the $R$ values are indicative of the phase purity of the film and do not represent the percentage of diamond in the coating.

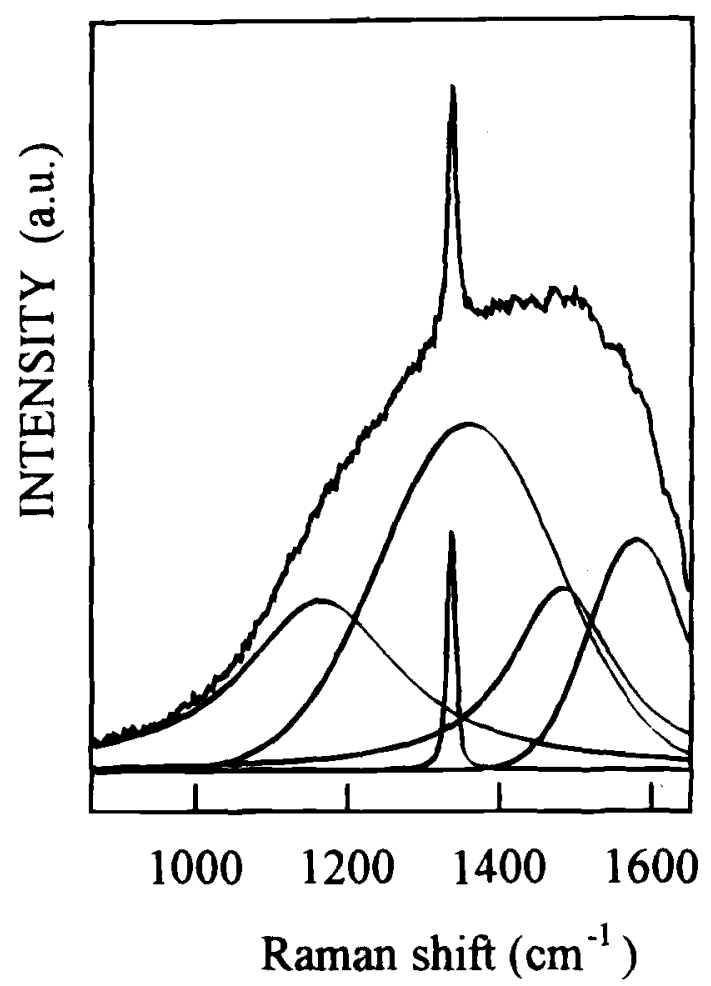

Fig. 3. Deconvolution of the Raman spectrum of the film grown with $0.5 \% \mathrm{CH}_{4}$ at $900^{\circ} \mathrm{C}$ on scratched WC-5.8 w/o Co $(\lambda=514.5 \mathrm{~nm})$.

Phase purity.-Figure 4 shows the effect of deposition temperature on the $R$ values for the films grown with $1.0 \%$ $\mathrm{CH}_{4}$ on $\mathrm{S}$ samples and with $0.5 \% \mathrm{CH}_{4}$ on $\mathrm{S}$ and $\mathrm{SE}$ samples. Repeated deposition runs carried out on different samples in the same conditions led to reproducible results with a scattering in the $R$ values lower than \pm 0.0025 (i.e., $0.25 \%$ ). As expected, at a given deposition temperature the amount of crystalline diamond is higher when $0.5 \% \mathrm{CH}_{4}$ is used in the feed gas. The trend of $R v s$. $T$ shows a maximum at around $750^{\circ} \mathrm{C}$, much more pronounced at the lower methane concentration. At lower as well as at higher temperatures a more abundant codeposition of nondiamond carbon occurred. Surprisingly, the phase purity increased again at the highest substrate temperature investigated $\left(950^{\circ} \mathrm{C}\right)$. The same trend of $R$ was also found on substrates etched prior to deposition (SE samples), with $R$ values very close to those obtained for $S$ samples. In order to clar-

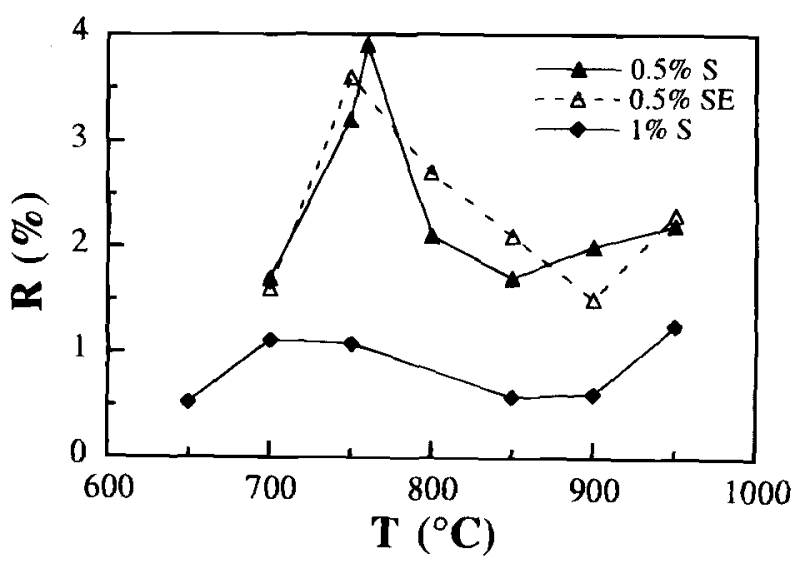

Fig. 4. Ratio (\%) of the integrated intensity of the diamond Raman peak over the total infegrated intensity of the carbonaceous components as a function of the substrate temperature. $\mathrm{CH}_{4}$ mole fraction in the feed gas and substrate pretreatments are indicated in the figure (S refers to the scratched samples and SE the scratched and etched substrates). 
ify this temperature dependence of the phase purity of diamond deposited on S and SE cemented carbide, it is important to recall here the conclusions drawn by Frenklach and Wang in their extensive study of diamond HFCVD on diamond. ${ }^{32}$ These authors showed that carbon deposits with high $\mathrm{sp}^{3} / \mathrm{sp}^{2}$ ratios can be obtained in a definite range of substrate temperatures and that the diamond-to-sp ${ }^{2}$-carbon ratio has a maximum at a given temperature whose value depends on deposition parameters. At low substrate temperatures, the deposition of amorphous $\mathrm{sp}^{2}$-carbon is due to the condensation of aromatic hydrocarbons formed in the thermally activated gas phase. At high temperatures, the decomposition of hydrogenated $\mathrm{sp}^{3}$-carbon atoms of the diamond surface leads to the formation of $\pi$-bonds and to the codeposition of an amorphous $\mathrm{sp}^{3} / \mathrm{sp}^{2}$ carbonaceous network. Therefore, the decrease of phase purity at the lower temperatures here investigated $\left(T \leq 700^{\circ} \mathrm{C}\right)$ is attributable to a more abundant condensation of aromatics. The steep decrease of the phase purity reported in Fig. 3 for substrate temperatures higher than $760^{\circ} \mathrm{C}$ and the increase of $R$ at $950^{\circ} \mathrm{C}$ are apparently in contrast with the findings of Ref. 32. In order to understand these results, we have to take into account the behavior of the binder phase and its interaction with diamond. Mehlmann et al. ${ }^{9}$ found that the quality of diamond films deposited with $1 \% \mathrm{CH}_{4}$ on unetched WC- $6 \%$ Co at $940^{\circ} \mathrm{C}$ was higher than that of films grown at $800^{\circ} \mathrm{C}$. These authors revealed the presence of cobalt particles surrounded by disordered graphite in the diamond film grown at the lower temperature. These Co-containing particles were not observed in the film deposited at $940^{\circ} \mathrm{C}$ and their absence was attributed to the in situ etching of cobalt performed by monohydrogen at the higher temperature. Park et $a l .{ }^{20}$ found that the quality of diamond films grown on unetched WC-5\% Co substrates increased with increasing the substrate temperature from 800 to $1100^{\circ} \mathrm{C}$. These results can be explained also considering the in situ etching of the binder phase claimed by Mehlmann et al. Therefore, the steep decrease of $R$ at deposition temperatures higher than $760^{\circ} \mathrm{C}$ should be ascribed to a faster binder diffusion into the growing film, thereby resulting in the formation of nondiamond carbon phases. At $950^{\circ} \mathrm{C}$, the increased etching rate of Co partly suppressed the deleterious effects of binder diffusion through the deposit.

It is worth noticing that the phase purity of films grown on etched substrates (SE samples) was comparable to that obtained on S samples under identical deposition conditions (Fig. 4). Pan et al. ${ }^{17}$ studied, by Auger electron spectroscopy (AES) and by cross-sectional transmission electron microscopy (XTEM), the diamond growth on pure WC and on wet-etched WC- $6 \%$ Co substrates deposited at 800 to $850^{\circ} \mathrm{C}$. Within the AES detection limit, the cemented WC substrate surface was free of Co prior to deposition. Nevertheless, these authors clearly put into evidence the formation of a Co-containing amorphous carbon layer at the diamond/substrate interface. This finding implies that under CVD conditions, cobalt diffuses from the bulk to the etched cemented carbide surface, promoting the formation of amorphous carbon. On the contrary, XTEM measurements revealed that diamond crystals were directly grown on pure WC. Zhu et al. ${ }^{33}$ studied the diamond deposition on binderless W-Mo composite carbide. Although the Co content in their substrates was below $0.1 \mathrm{w} / \mathrm{o}$, after $8 \mathrm{~h}$ deposition at $985^{\circ} \mathrm{C}$ the Co content at the diamond/substrate interface was 2 to 4 atomic percent (a/o) as revealed by AES. The increase of the Co concentration at the interface after deposition suggests that Co segrates from within the substrate to the surface. Therefore, due to the high mobility of Co during CVD, the preliminary etching does not significantly increase the phase purity of diamond coatings.

Crystallinity of the deposited diamond.-Figure 5 shows the variation of the FWHM of diamond Raman peak with the substrate temperature. It is evident that the diamond Raman linewidth increases monotonically with deposition

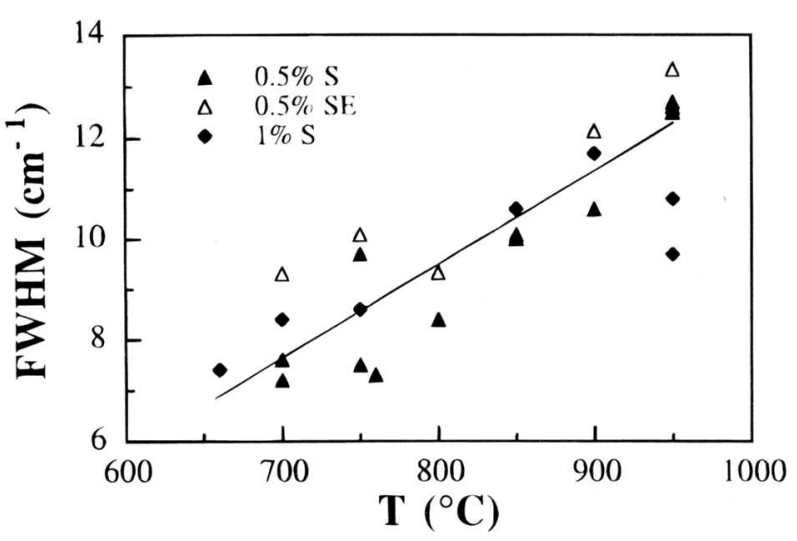

Fig. 5. FWHM of the first-order Raman diamond peak as a function of the substrate temperature. $\mathrm{CH}_{4}$ mole fraction in the feed gas and substrate pretreatments are indicated in the figure $(S$ refers to the scratched samples and SE the scratched and etched substrates).

temperature with a broadening rate of $\sim 2 \mathrm{~cm}^{-1} / 100^{\circ} \mathrm{C}$. The performance of the preliminary etching (SE samples) as well as the use of $0.5 \% \mathrm{CH}_{4}$ instead of $1.0 \% \mathrm{CH}_{4}$ in the feed gas did not significantly affect the FWHM of the diamond peak. A similar trend was also observed for diamond films grown on $\mathrm{Ni}$-cemented $\mathrm{WC}$ in the 650 to $850^{\circ} \mathrm{C}$ temperature range. ${ }^{34}$

Figure 6 shows the surface morphology of well-faceted diamond coatings deposited on $\mathrm{S}$ samples with $0.5 \% \mathrm{CH}_{4}$ at 760 and $900^{\circ} \mathrm{C}$, indicating that the increase in deposition temperature caused a grain coarsening. This finding is apparently contradicted by the variation of the diamond Raman linewidth with the substrate temperature.

It is a well-established fact that the width of the firstorder Raman band increases as the average size of crys-
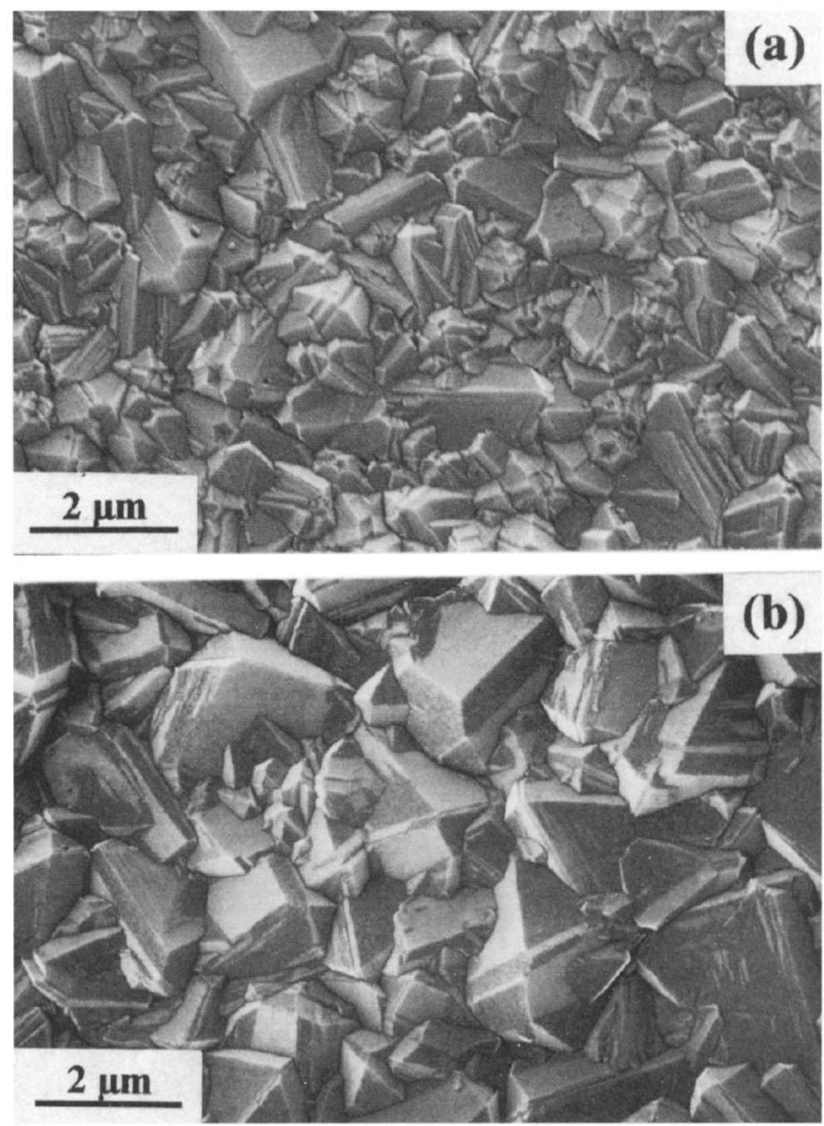

Fig. 6. SEM micrographs of diamond coatings deposited on scratched (S) samples at (a) 760 and (b) $900{ }^{\circ} \mathrm{C}\left(0.5 \% \mathrm{CH}_{4}\right)$. 
talline domains decreases. ${ }^{29.35}$ Ascarelli et al..$^{36}$ proposed a phonon diffusion model to explain the reverse relationship between these two quantities. As reported by Bachmann, ${ }^{35}$ the line broadening could also arise from an inhomogenous internal stress of crystallites in the coating. In our samples, the observed 6.4 to $13.3 \mathrm{~cm}^{-1}$ broadening should correspond to a stress distribution of $3.9 \pm 1.4 \mathrm{GPa}$, assuming a pressure coefficient of $2.5 \mathrm{~cm}^{-1} / \mathrm{GPa}$. Because the average compressive stress determined by the diamond line shift $\left(1337 \mathrm{~cm}^{-1}\right)$ is about $2 \mathrm{GPa}$ and considering the largely symmetrical lineshape of the measured diamond peaks, we conclude that the line broadening cannot be attributed to such internal stress distribution but to defects like vacancies, dislocations, twinnings, and stacking faults. Therefore, the combined use of SEM and Raman analysis indicates that larger grains grown at higher deposition temperatures exhibit a higher density of defects, independently of their size.

\section{Conclusions}

Diamond films have been deposited by HFCVD on ISOgrade $\mathrm{K} 10$ cemented carbide $(94.2 \mathrm{w} / \mathrm{o}$ WC-5.8 w/o Co) using $0.5 \%$ or $1.0 \% \mathrm{CH}_{4} / \mathrm{H}_{2}$ in the 650 to $950^{\circ} \mathrm{C}$ substrate temperature range. The diamond Raman shift $\left(1337 \mathrm{~cm}^{-1}\right)$ indicated a $2 \mathrm{GPa}$ residual compressive stress in the films. The amount of codeposited nondiamond carbon phases was strongly affected by the deposition parameters, namely, the $\mathrm{CH}_{4}$ content in the gas phase and the substrate temperature. The performance of a preliminary etching of the substrates with diluted nitric acid did not allow the deposition of purer diamond films. This finding has been attributed to the diffusion of the binder from the bulk to the substrate surface during the CVD process. High-purity diamond coatings have been obtained using $0.5 \% \mathrm{CH}_{4}$ and in a rather narrow substrate temperature range $(750$ to $760^{\circ} \mathrm{C}$ ). At lower as well as at higher temperatures, a more abundant codeposition of nondiamond carbon phases occurred. At $950^{\circ} \mathrm{C}$ the film quality increased again. This fact was ascribed to the in situ etching of Co performed by monohydrogen. From a practical point of view, this occurrence suggests that it is more convenient to perform diamond deposition on cemented tungsten carbide above $900^{\circ} \mathrm{C}$ rather than below $750^{\circ} \mathrm{C}$, also considering the higher deposition rates at higher temperatures. ${ }^{19}$ The density of defects in the deposited diamond, as indicated by the diamond Raman line broadening, increased with the substrate temperature. Therefore, in order to grow purer diamond films, a careful selection of the deposition conditions is much more effective than the wet etching of the substrate prior to CVD.

Manuscript July 22, 1996; revised manuscript received Jan. 2, 1997.

Universitá di Roma assisted in meeting the publication costs of this article.

\section{REFERENCES}

1. H. Matsubara and T. Sakuma, J. Mater. Sci, 25, 4472 $(1990)$

2. C.-T. Kuo, T.-Y. Yen, T.-H. Huang, and S. E. Hsu, J. Mater. Res., 5, 2515 (1990).

3. T. Leyendecker, O. Lemmer, A. Jürgens, S. Esser, and J. Ebberink, Surf. Coat. Technol., 48, 253 (1991).

4. B. Lux and R. Haubner, Phil. Trans. R. Soc. Lond., A342, 297 (1993).

5. K. Miyoshi, R. L. C. Wu, A. Garscadden, P. N. Barnes, and H. E. Jackson, J. Appl. Phys., 74, 4446 (1993)

6. T. H. Huang, C.-T. Kuo, and T. S. Lin, Surf. Coat. Technol., 56, 105 (1993).
7. N. M. Everitt, R. F. Silva, J. Vieira, C. A. Rego, C. R. Henderson, and P. W. May, Diamond Relat. Mater., 4, 730 (1995)

8. M. Kawarada, K. Kurihara, and K. Sasaki, ibid., 2, 1083 (1993).

9. A. K. Mehlmann, S. Berger, A. Fayer, S. F. Dirnfeld, M. Bamberger, Y. Avigal, A. Hoffman, and R. Porath, ibid., 3, 805 (1994).

10. S. Kubelka, R. Haubner, B. Lux, R. Steiner, G. Stingeder, and M. Grasserbauer, Diamond Film Technol., 5, 105 (1995).

11. T. Isozaki, Y. Saito, A. Masuda, K. Fukumoto, T. Ito, E. J. Oles, A. Inspector, and C. E. Bauer, Diamond Relat. Mater., 2, 1156 (1993).

12. E. R. Kupp, W. R. Drawl, and K. E. Spear, Surf. Coat. Technol., 68/69, 378 (1994).

13. S. Kubelka, R. Haubner, B. Lux, R. Steiner, G. Stingeder, and M. Grasserbauer, Diamond Relat. Mater., 3, 1360 (1994).

14. K. Shibuki, M. Yagi, K. Saijo, and S. Takatsu, Surf. Coat. Technol., 36, 295 (1988).

15. H. Matsubara and J. Kihara, in Science and Technology of New Diamond, S. Saito, O. Fukunaga, and M. Yoshikawa, Editors, p. 89, KTK Scientific Publishers/Terra Scientific Publishing Company, Tokyo (1990).

16. A. K. Mehlmann, S. F. Dirnfeld, and Y. Avigal, Diamond Relat. Mater., 1, 600 (1992).

17. F.-M. Pan, J.-L. Chen, T. Chou, T.-S. Lin, and L. Chang, $J$. Vac. Sci. Technol., A12, 1519 (1994).

18. R. Polini, G. Marcheselli, and E. Traversa, J. Am. Ceram. Soc., 77, 2043 (1994).

19. R. Polini, G. Marcheselli, G. Mattei, and E. Traversa, ibid., 78, 2341 (1995).

20. B. S. Park, Y.-J. Baik, K.-R. Lee, K. Y. Eun, and D. H. Kim, Diamond Relat. Mater, 2, 910 (1993).

21. K. Tanabe and J. Hiraishi, Appl. Spectrosc., 35, 436 (1981); A. K. Arora and V. Umadevi, ibid., 36, 424 (1982); K. Tanabe and J. Hiraishi, J. Raman Spectrosc., 12, 274 (1982); and B. P. Asthashana and W. Kieffer, Appl. Spectrosc., 36, 250 (1982).

22. D. S. Knight and W. B. White, J. Mater. Res., 4, 837 (1989).

23. J. W. Ager III and M. D. Drory, Phys. Rev. B, 48, 2601 (1993).

24. H. Mohrbacher, K. Van Acker, B. Blanpain, P. Van Houtte, and J-P. Celis, J. Mater. Res., 11, 1776 (1996)

25. S. K. Sharma, H. K. Mao, P. M. Bell, and J. A. Xu, J. Raman Spectrosc., 16, 350 (1985).

26. A. Tardieu, F. Cansell, and J. P. Petitet, J. Appl. Phys., 68, 3243 (1990).

27. H. Windischmann and K. J. Gray, Diamond Relat. Mater., 4, 837 (1995).

28. H. Henchen, Thin Solid Films, 212, 206 (1990)

29. P. K. Bachmann and D. U. Wiechert, Diamond Relat. Mater., 1, 422 (1992).

30. R. J. Nemanich, J. T. Glass, G. Lucovsky, and R. E. Schroder, J. Vac. Sci. Technol., A6, 1783 (1988).

31. J. I. Pankove and C.-H. Qiu, in Synthetic Diamond: Emerging CVD Science and Technology, K. E. Spear and J. P. Dismukes, Editors, p. 401, John Wiley \& Sons, New York (1994)

32. M. Frenklach and H. Wang, Phys. Rev. B, 43, 1520 (1991).

33. W. Zhu, R. C. McCune, J. E. deVries, M. A. Tamor, and K. Y. Simon Ng, Diamond Relat. Mater., 3, 1270 (1994).

34. R. Polini, G. Marcheselli, A. Marucci, G. Mattei, and E. Traversa, in Fourth Euro Ceramics/1995, Vol. 9Coatings and Joinings, B. S. Tranchina and A. Bellosi, Editors, p. 281, Gruppo Editoriale Faenza Editrice S.p.A., Faenza, Italy (1995).

35. P. K. Bachmann, H. D. Bausen, H. Lade, D. Leers, D. U. Wiechert, N. Herres, R. Kohl, and P. Koidl, Diamond Relat. Mater., 3, 1308 (1994).

36. P. Ascarelli, E. Cappelli, G. Mattei, F. Pinzari, and S. Martelli, ibid., 4, 464 (1995) 